\title{
Multiple endosymbionts in populations of the ant Formica cinerea
}

Anu Sirviö ${ }^{*}$, Pekka Pamilo ${ }^{1,2}$

\begin{abstract}
Background: Many insects, including ants, are infected by maternally inherited Wolbachia endosymbiotic bacteria though other secondary endosymbionts have not been reported in ants. It has been suggested that the ability of Wolbachia to invade and remain in an ant population depends on the number of coexisting queens in a colony. We study the genetic and social structure of populations in the ant Formica cinerea which is known to have populations with either monogynous or polygynous colonies. We screen populations for several endosymbiotic bacteria to evaluate the presence of different endosymbionts, possible association between their prevalence and the social structure, and the association between endosymbiont prevalence and genetic differentiation of ant populations.

Results: We found three endosymbiotic bacteria; 19\% of the nests were infected by Wolbachia, 3.8\% by Cardinium and $33 \%$ by Serratia. There was significant variation among the populations regarding the proportion of nests infected by Serratia, Wolbachia and the pooled set of all the endosymbionts. Some individuals and colonies carried two of the bacteria, the frequency of double infections agreeing with the random expectation. The proportion of infected ants (individuals or colonies) did not correlate significantly with the population level relatedness values. The difference in the prevalence of Wolbachia between population pairs correlated significantly with the genetic distance (microsatellites) of the populations.

Conclusions: The discovery of several endosymbionts and co-infections by Wolbachia and Cardinium demonstrate the importance of screening several endosymbionts when evaluating their possible effects on social life and queen-worker conflicts over sex allocation. The low prevalence of Wolbachia in F. cinerea departs from the pattern observed in many other Formica ants in which all workers have been infected. It is likely that the strain of Wolbachia in F. cinerea differs from those in other Formica species. The correlation between the difference in Wolbachia prevalence and the pair-wise genetic distance of populations suggests that spreading of the bacteria is restricted by the isolation of the host populations.
\end{abstract}

\section{Background}

Insects carry several endosymbiotic bacteria which can affect the life of their hosts [1]. Primary (or obligate) endosymbionts are usually mutualistic, host-specific and are restricted to vertical transmission in the maternal line and have long-term coevolution with their host. These include Buchnera in aphids, Blochmannia in Camponotus carpenter ants, Wigglesworthia glossinidium in tsetse flies and Baumannia cicadellinicola in leafhoppers [2]. Secondary (or facultative) endosymbionts can be either

\footnotetext{
* Correspondence: anu.sirvio@oulu.fi

'Department of Biology, P.O. Box 3000, University of Oulu 90014, Oulu, Finland

Full list of author information is available at the end of the article
}

parasitic or mutualistic, they are found in a variety of host taxa, and are characterised by obvious horizontal transmission. Screening of secondary endosymbionts in insects is often restricted to Wolbachia which is inherited vertically from mother to offspring and can manipulate the reproduction of the host in ways that increase the number of female offspring [3]. Other secondary endosymbionts, including Rickettsia, Spiroplasma and Cardinium have been found in various groups of arthropods and they are also characterized by vertical transmission and reproductive manipulation [1]. They have been shown to induce cytoplasmic incompatibility, parthenogenesis, feminisation of male embryos and male killing $[2,4]$. In addition to the manipulation of reproduction, 
some of the secondary endosymbionts can give direct benefits to the host by delivering nutrients, by giving defence against natural enemies, by improving thermal tolerance, by enhancing fecundity and by inducing variation in breeding behaviour of the host $[2,5]$. Such features have raised questions about the role of endosymbiotic bacteria in inducing and controlling various phenotypic features of their arthropod hosts.

Reproductive manipulation by endosymbionts can be particularly important in the evolution of social Hymenoptera (ants, social bees and wasps) as it interferes with the sex ratio conflict between queens and workers $[3,6,7]$. Queens have commonly equal interest in the production of both sexes but workers can manipulate the sex ratio by preferentially caring either male or female larvae according to the relatedness asymmetry. If relatedness between nest mates is high workers favor the survival of females and when it is low they may care more male offspring. Workers of many social insect species do not reproduce, and if they do, they produce haploid males and thus prevent vertical transmission of endosymbionts. Yet, workers are numerous and form an important source for horizontal transmission. Mutualistic endosymbionts can also enhance the evolution of social behaviour and group living by forcing individuals to interact in order to obtain or receive benefits delivered by beneficial bacteria [see [8]].

Cytoplasmic incompatibility appears to be the most widespread Wolbachia-induced manipulation in insects and causes a serious load on the host population when the prevalence is close to $50 \%$ and incompatible matings are common. Selection is therefore expected to drive the prevalence towards zero or $100 \%$ [9]. In social insects colonies with many reproductive queens (polygynous colonies), the cost of incompatible mating can be reduced if other queens in the colony have compatible mating and produce a healthy colony. Based on this argument, it has been suggested that ants with polygynous colonies may have an intermediate prevalence of Wolbacia infection, whereas ants with monogynous colonies suffer from incompatible mating and should either lack infection or be all infected [10,11]. It should, however, be pointed out that the influence of Wolbachia on ant hosts has not been confirmed yet. Few laboratory and molecular studies have been done, without clear results despite widespread occurrence of different Wolbachia strains in various ant species [12]. So far, the studies have largely focused on the prevalence and patterns of transmission [13-16]. There are very few studies that have examined infection of social insects by bacteria other than Wolbachia $[3,17,18]$ or the overall diversity of microorganisms in ants $[19,20]$.

Because of the potential importance of endosymbiotic bacteria in social insect biology, we aimed to study the prevalence of several host-manipulating endosymbionts in the ant Formica cinerea, known also as the velvet or silky ant. The species inhabits open sandy areas and is distributed from South Western Asia to Central Europe, with local and seemingly isolated populations in northern Europe. Even though isolated on the map, the North-European populations have been found to be genetically relatively homogeneous with no obvious long-term isolation [21]. Formica cinerea is on a short list of ant species in which the social organisation of colonies varies among populations in such a way that colonies in some populations normally have a single queen (monogynous type) while they have multiple queens (polygynous type) in other populations [21,22]. This allows testing the hypotheses relating the prevalence of endosymbionts to the colonial type. Our study included ten populations in one geographical area (at most $50 \mathrm{~km}$ distance between populations) and we characterised the social type of colonies and inferred the gene flow between populations by using genetic markers (nuclear and mitochondrial), and screened the occurrence of several endosymbionts. Major questions we aimed to answer were: 1) Are there multiple endosymbionts in F. cinerea and do the endosymbionts compete with each other or do multiple infections occur frequently? 2) Is the prevalence of endosymbionts associated with the social type of colonies and is there any association between the prevalence of endosymbionts and the genetic distance between pairs of populations? Furthermore, we tested whether the social type influences gene flow in the ants as observed in other socially polymorphic ants [23]. We found three endosymbiotic bacteria (Candidatus Cardinium, Candidatus Serratia symbiotica and Wolbachia) infecting F. cinerea. This is the first study reporting potentially manipulative endosymbionts other than Wolbachia in ants.

\section{Results}

\section{Genetic structure of the ant populations}

The total number of alleles per microsatellite locus varied between 8 (FL20) and 12 (Fe16) across all the populations, and single populations had from 3 to 9 alleles per locus. The overall inbreeding coefficient was significantly positive in population 5 (Koppana sand pit, $\mathrm{F}=0.16$ with $95 \%$ CI $0.06-0.27$ ) (Table 1). The statistical tests are problematic because related individuals are not independent of each other, but there was no clear tendency for any specific locus to show departures from the expected Hardy-Weinberg frequencies.

Mean genetic relatedness ( $r$ ) of colonial nest-mates within populations varied from 0.04 to 0.59 (Table 1) indicating different social forms in the populations. The relatedness estimates divided the populations in two groups (Table 1). The relatedness estimates in Tauvo ( $r$ 
Table 1 Sample size, genetic characteristics of the ant populations and the number of nests affected by the endosymbionts

\begin{tabular}{|c|c|c|c|c|c|c|c|c|c|c|c|c|c|}
\hline \multicolumn{2}{|c|}{ Population } & \multirow[t]{2}{*}{$\mathrm{N}_{\mathrm{n}}$} & \multirow[t]{2}{*}{$\mathbf{N}_{\text {all }}$} & \multirow[t]{2}{*}{$\mathrm{H}_{\exp }$} & \multicolumn{2}{|c|}{$\mathbf{r}$} & \multirow[t]{2}{*}{$\mathbf{F}$} & \multicolumn{6}{|c|}{ Number of infected nests } \\
\hline & & & & & mean & se & & Serr & Wolb & Card & SW & SC & $W C$ \\
\hline 1 & Juurussuo & 22 & 28 & 0.74 & 0.54 & 0.06 & 0.02 & 7 & 2 & 2 & 0 & 1 & 1 \\
\hline 2 & Koppana beach & 20 & 23 & 0.73 & 0.12 & 0.03 & -0.01 & 7 & 6 & 1 & 3 & 1 & 0 \\
\hline 3 & Haukipudas & 20 & 24 & 0.75 & 0.49 & 0.07 & 0.00 & 2 & 5 & 0 & 1 & 0 & 0 \\
\hline 4 & Jääli & 17 & 26 & 0.73 & 0.45 & 0.05 & 0.04 & 4 & 2 & 0 & 1 & 0 & 0 \\
\hline 5 & Koppana sand pit & 16 & 27 & 0.75 & 0.40 & 0.08 & 0.16 & 13 & 1 & 1 & 0 & 1 & 0 \\
\hline 6 & Liminka & 9 & 17 & 0.67 & 0.59 & 0.05 & -0.16 & 0 & 2 & 0 & 0 & 0 & 0 \\
\hline 7 & Mäntyniemi (Hailuoto) & 9 & 26 & 0.55 & 0.44 & 0.09 & -0.01 & 5 & 6 & 0 & 4 & 0 & 0 \\
\hline 8 & Tauvo & 12 & 23 & 0.70 & 0.04 & 0.04 & 0.01 & 3 & 0 & 0 & 0 & 0 & 0 \\
\hline 9 & Keskiniemi (Hailuoto) & 3 & 16 & 0.60 & - & - & - & 1 & 0 & 0 & 0 & 0 & 0 \\
\hline 10 & Huilunnokka (Hailuoto) & 4 & 17 & 0.71 & - & - & - & 1 & 1 & 1 & 0 & 0 & 1 \\
\hline
\end{tabular}

$\mathrm{N}_{\mathrm{n}}$ and $\mathrm{N}_{\text {all }}$ refer to the number of nests and microsatellite alleles. Five worker ants were screened from each nest. $H_{\exp }=$ expected heterozygosity, $r=$ relatedness and $\mathrm{F}=$ inbreeding coefficient. The standard error of relatedness was obtained by jackknifing over the nests. Number of infected nests is given for each bacterium (Serr, Wolb, Card) and for double infections (SW, SC and WC).

$=0.04)$ and Koppana beach $(\mathrm{r}=0.12)$ were significantly smaller than in the other six populations (in which $r \geq$ 0.40 ), whereas there were no significant relatedness differences among the populations within the two groups (pair-wise comparisons with $t$-test). The level of polygyny in the Koppana sand pit population was unclear as the estimate of relatedness was $r=0.40$ but there was also an excess of homozygotes, and the inbreedingadjusted relatedness [24] was $\mathrm{r}^{*}=0.17$. The high initial relatedness, however, indicates that the nests were genetically separate and did not form colonial networks exchanging workers.

Colonies within populations had a wide range of relatedness values, but it should be noted that such individual estimates have a large sampling variance. The two populations with low average worker relatedness had $10 \%$ of nests (3 out 32 ) with relatedness $r>0.3$. Likewise, the six populations with a high average relatedness had $10 \%$ of nests ( 8 out of 82 ) with relatedness $r<0.11$.

The pair-wise estimates of $\mathrm{F}_{\mathrm{ST}}$ ranged from 0.01 to 0.17 (Table 2). Populations $1,3,4$ and 5 did not differ significantly from each other (permutation test, $\mathrm{P}>$ 0.05 ), but the other populations showed significant differences $\left(\mathrm{F}_{\mathrm{ST}}\right.$ larger than obtained by permutation of the

Table 2 Pair-wise genetic differentiation $\left(F_{S T}\right)$ of the ant populations

\begin{tabular}{rrrrrrrr}
\hline & $\mathbf{1}$ & $\mathbf{2}$ & $\mathbf{3}$ & $\mathbf{4}$ & $\mathbf{5}$ & $\mathbf{6}$ & $\mathbf{7}$ \\
\hline 2 & 0.033 & & & & & & \\
3 & 0.011 & 0.020 & & & & & \\
4 & 0.013 & 0.056 & 0.009 & & & & \\
5 & 0.010 & 0.036 & 0.008 & 0.005 & & & \\
6 & 0.041 & 0.108 & 0.051 & 0.091 & 0.056 & & \\
7 & 0.110 & 0.154 & 0.084 & 0.059 & 0.068 & 0.149 & \\
8 & 0.009 & 0.023 & 0.018 & 0.066 & 0.033 & 0.045 & 0.169 \\
\hline
\end{tabular}

nests) to any other population. The population on the island of Hailuoto (7, Mäntyniemi) was the most differentiated population (Table 2, Additional File 1). The correlation between the genetic distance and the geographical distance was not significant $\left(\mathrm{r}_{\mathrm{m}}=0.20, \mathrm{P}=0.25\right.$, Mantel's test). Notably, the two closely located Koppana populations ( 2 and 5 ) that were separated by only 1.5 $\mathrm{km}$ differed significantly from each other with $\mathrm{F}_{\mathrm{ST}}=$ 0.05 .

The mitochondrial sequences revealed five haplotypes A-E (Additional file 2) [GenBank: haplotype A: GU592755, B: GU592752, C: GU592754, D: GU592751 and E: GU592753]. Haplotype E was prevailing and included most samples from all the populations. Haplotype A was found in four individuals from two colonies of population 4 (Jääli) and had a single transition in the tRNA-Ser part of the amplified region. Haplotypes B and $C$ had single nucleotide changes, both leading to an amino acid change (I to V and L to I). Haplotype B was detected in individuals from four colonies of population 5 (Koppana sand pit). Haplotype $C$ occurred in two populations, in individuals from four colonies of population 1 (Juurussuo) and from three colonies of population 4 (Jäli). Haplotype D could be derived from the haplotype $\mathrm{C}$ by a synonymous transition and was observed in only a single colony in population 3 (Haukipudas). In the populations that had two haplotypes, only one haplotype was found in each nest.

\section{Wolbachia}

No amplification was initially detected when the $w s p$-primer pair was used for all $656 F$. cinerea individuals, while positive controls (F. aquilonia, $F$. rufa, F. polyctena, F. lugubris, F. paralugubris, F. lemani) produced a strong band that was confirmed to belong to Wolbachia by sequencing. Different concentrations (20-60 ng/ul) of genomic template were tested for a 
subset of samples, as well as different annealing temperatures $\left(50-60^{\circ} \mathrm{C}\right)$ and several $\mathrm{MgCl}_{2}$ concentrations (1-3 mM) but PCR produced either almost invisibly faint bands that had a correct fragment size or mostly no bands at all for F. cinerea wsp. When hemi-nested PCR with several bacteria-specific primer pairs was used to amplify $16 \mathrm{SrDNA}$, we successfully amplified Wolbachia, Serratia and Cardinium from F. cinerea. The other bacteria (Ricketsia, Spiroplasma, Buchnera) were not detected.

Wolbachia was found in eight out of ten populations and the proportion of infected individuals in those ranged from $1.2 \%$ (population 5) to 33\% (population 7) (Table 1, Figure 1). In total, 5.6\% of the individuals and $19 \%$ of the nests were infected by Wolbachia. Some singleton sites of the obtained sequence $(896 \mathrm{bp})$ can represent PCR errors, but there were 49 parsimony informative sites. Among the haplotypes, four from Liminka (population 6) differed from all the others at 21-27 sites (mean difference $\mathrm{p}=0.025$ ). Among the other haplotypes, the largest number of pair-wise nucleotide differences was $13(\mathrm{p}=0.014)$ and the largest differences were between sequences from Haukipudas (population 3) and the island of Hailuoto (populations $7,10)$. In a neighbour-joining tree, the sequences from these two areas tended to form groups of their own, otherwise there were no clear geographical groupings (Additional file 3). A BLAST search showed that the majority of Wolbachia sequences of the 16SrDNA from F. cinerea [GenBank GU592769-GU592781] were 98-

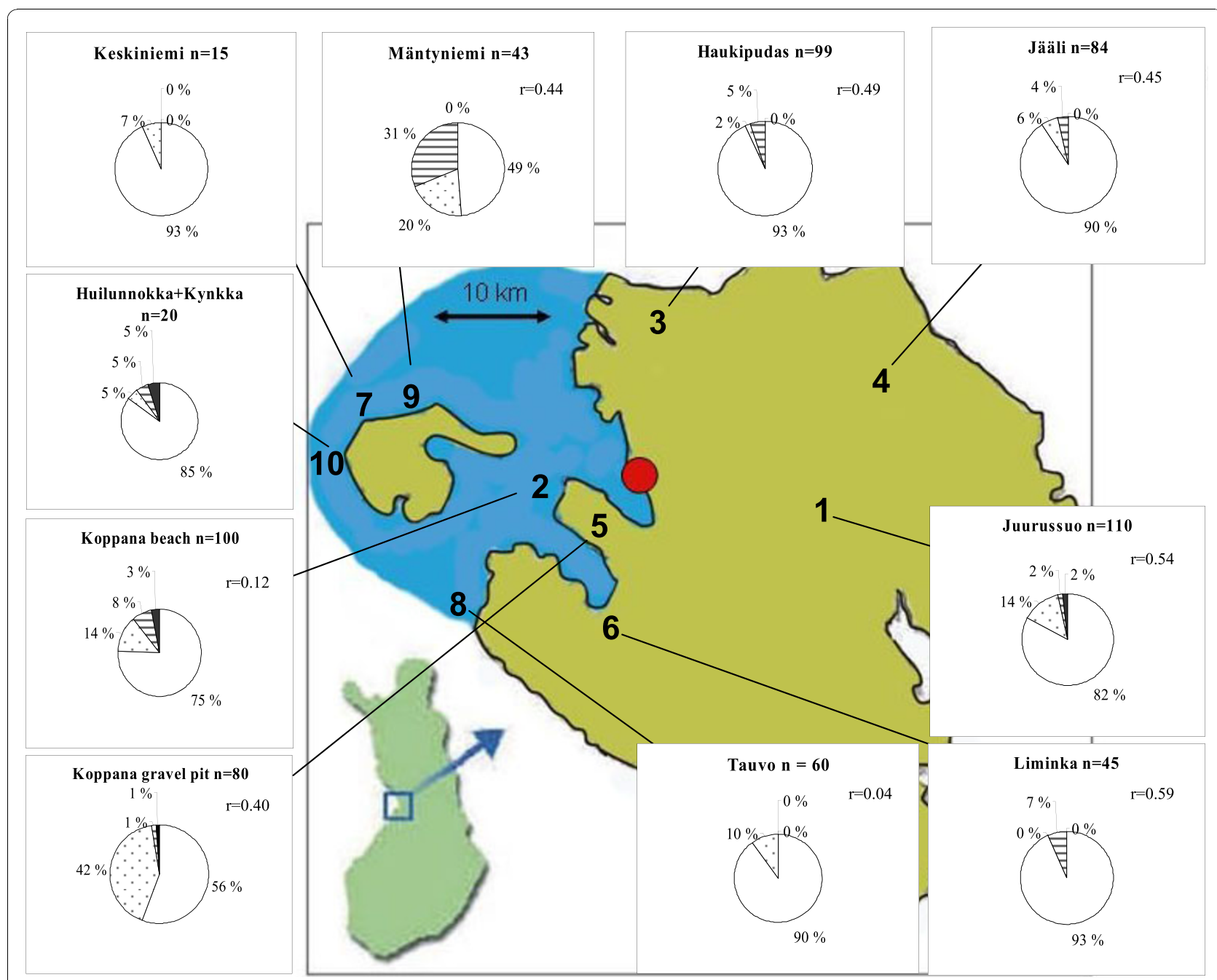

Figure 1 Infection percentages and the relatedness values in $F$. cinerea populations. The percentage of individuals infected by different endosymbionts are shown as segments in pie diagrams where the dotted areas represent Candidatus Serratia symbiotica, horizontal lines Wolbachia, black areas Cardinium and the white areas uninfected individuals. The relatedness values and the total number of individuals are shown for each population. The segments of the diagrams do not properly take into account the few individuals that were multiply infected. The scale of the map is proportional. 
99\% similar to Wolbachia-like uncultured bacterial clones from the ant lion Myrmeleon mobilis, fly Cacoxenus indagator, and giant scale insect Drosicha pinicola as well as to Wolbachia from several Drosophila species and Diabroticite beetles (Additional files 3, 4 and 5).

In order to compare the Wolbachia in F. cinerea with the strains found earlier in other Formica ants, we sequenced bacteria from several Formica species (F. aquilonia: Finland, F. polyctena: Russia and Sweden, F. lugubris: France, F. rufa: Russia) that were known to carry different $w F e x$-strains of Wolbachia determined by the $w s p$ sequences [[15] and our unpublished sequences for $F$. aquilonia]. The $16 \mathrm{SrDNA}$ sequences obtained from these hosts were either identical to one of the sequences found in the major group from $F$. cinerea or differed by only one nucleotide (see Additional file 5). [GenBank:F. rufa GU592782, F. aquilonia GU592783GU592785, F. lugubris GU592786, F. polyctena GU592787-GU592788, F. lugubris GU592789]. The deviating sequences from the Liminka population of F. cinerea fell outside this group.

\section{Cardinium}

Cardinium was present in seven individuals that came from four populations (1, 2, 5 and 10), and the proportion of infected individuals ranged from 1.3\% (population 5) to $5 \%$ (population 10) (Table 1, Figure 1). In total, only $1.1 \%$ of the individuals and $3.8 \%$ of the nests were infected. The sequences $(450 \mathrm{bp})$ had 11 parsimony informative sites [GenBank GU592742GU592750]. The neighbour-joining tree of the haplotypes showed no clear geographical pattern.

The maximum number of pair-wise nucleotide differences was ten $(p=0.022$, total length $450 \mathrm{bp})$. The parsimony informative sites separated three haplotypes in the Juurussuo population (population 1) from the others by five specific differences. The main group of sequences was $98-99 \%$ similar to Cardinium sequences obtained earlier from several species of Brevipalpus mites, Metaseiulus occidentalis, leafhopper Scaphoideus titanus and spider mite Oligonychus ilicis (Figure 2, Additional file 6).

\section{Serratia}

Sequences produced by the PASS primers [GenBank GU592756-GU592768] gave 98\% similarities with symbiont S from Acyrthosiphon pea aphid (M27040), secondary symbiont type-R of Aphis craccivora (AY822593, AY822592, AY822591, AY822594), secondary symbiont of Acyrthosiphon pisum (AB033777, AB033778), and Candidatus Serratia symbiotica (AF293617, AY296732) (see Additonal file 7). Thus our sequences could be considered to belong to the recently named new species Candidatus Serratia symbiotica (formerly known as PASS or R-type secondary symbiont of aphids) [25]. Serratia was found in all populations except Liminka

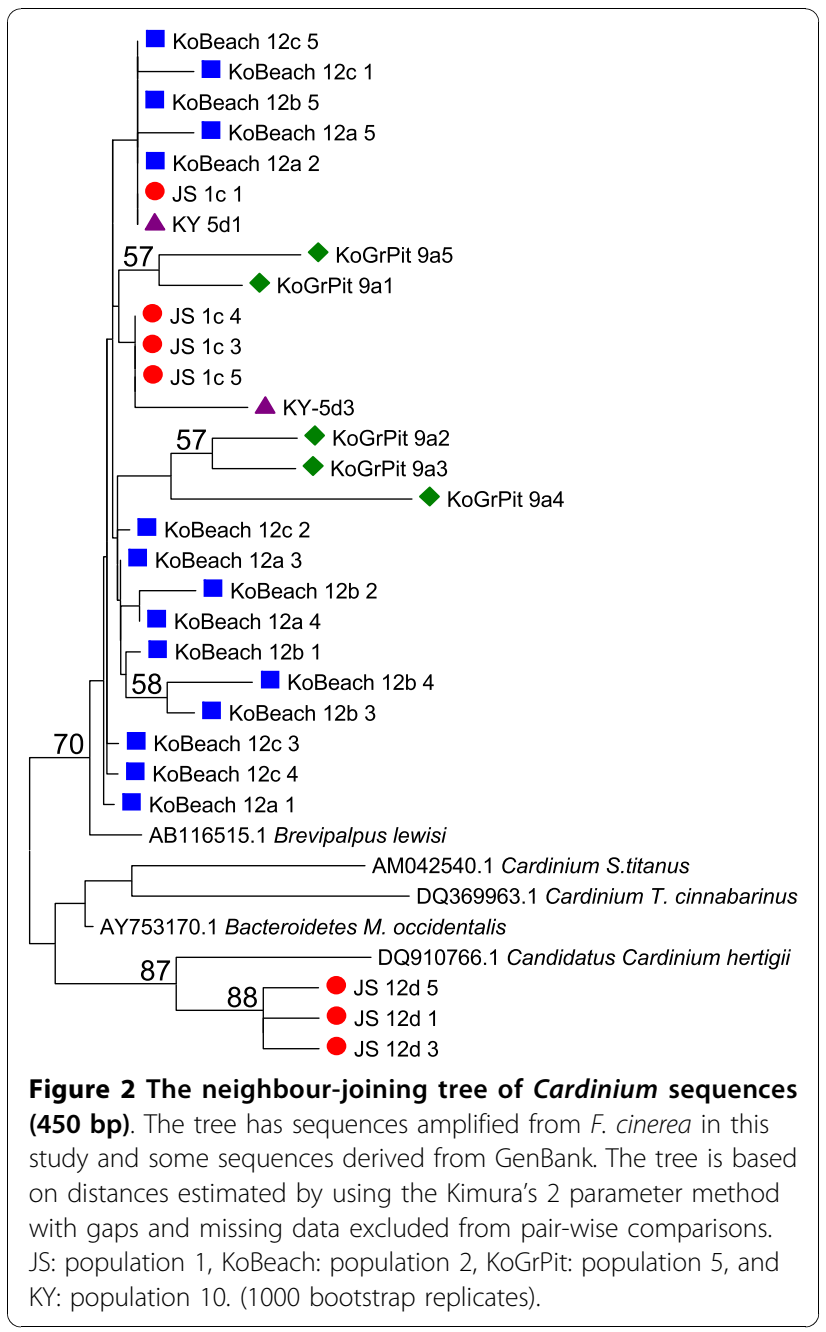

(population 6). Not all the nests in the infected populations had Serratia, and the proportion of infected individuals within populations ranged from $2 \%$ (population 3 , Haukipudas) to $43 \%$ (population 5, Koppana sand pit) (Table 1, Figure 1), and a total of $13.2 \%$ of all the $F$. cinerea individuals and 33\% of the nests were infected.

The sequence ( $471 \mathrm{bp}$ ) had 19 parsimony informative sites. The largest pair-wise difference was 7 nucleotides $(p=0.014)$, and the neighbour-joining tree showed no clear geographical clustering of the haplotypes (Additional file 8).

\section{Connections with the genetic structure of the ant populations and multiple infections}

There was significant variation among the populations regarding the fraction of nests infected by Serratia $\left(\chi^{2}=\right.$ $26.2, \mathrm{df}=7, \mathrm{P}<0.001)$, by Wolbachia $\left(\chi^{2}=21.7, \mathrm{df}=7\right.$, $\mathrm{P}<0.01)$ and by the pooled set of all the endosymbionts $\left(\chi^{2}=21.0, \mathrm{df}=7, \mathrm{P}<0.01\right)$. The infection frequencies of the two most common endosymbionts, Serratia and 
Wolbachia, showed no significant correlation when the frequencies of infected nests in the eight populations were compared (Spearman's $\mathrm{r}_{\mathrm{s}}=-0.09$, $\mathrm{df}=6, \mathrm{~ns}$ ).

We next tested whether the observed heterogeneity in the infection frequencies was correlated with the genetic structure of the ant populations. No significant correlation between the fraction of infected nests and the mean relatedness in the eight populations was observed $\left(r_{s}=-0.45\right.$ for Serratia, $r_{s}=0.19$ for Wolbachia and $r_{s}=$ -0.43 when pooling all the endosymbionts, $\mathrm{df}=6, \mathrm{~ns}$ ). As the power of the test at the level of populations may be restricted by the small number of populations, we also tested for a possible association by pooling populations. For this we used only populations with a somewhat similar average relatedness $(0.40<\mathrm{r}<0.59)$ and tested whether the relatedness estimates calculated for each nest were different in infected and non-infected nests. No significant difference was found when testing for Serratia, Wolbachia or all the endosymbionts (Mann-Whitney test).

The number of workers infected by Serratia in a nest showed significant positive correlation with the nest relatedness in population 7 (Mäntyniemi) (Spearman $r_{s}$ $=0.70, \mathrm{n}=9, \mathrm{P}<0.05)$. No significant correlation was found in other populations or for Wolbachia infections.

Infection by all three bacteria was not found in any individuals or colonies, though some double infections were found within both individuals and colonies. Serratia-Wolbachia infections were detected in some individuals from population 7 (Mäntyniemi, 2 individuals out of 43), population 3 (Haukipudas, 1/99) and population 4 (Jääli, 1/84). Double infection by Serratia and Cardinium was found only in population 1 (Juurussuo) where a single ant out of 110 carried both bacteria. Wolbachia-Cardinium double infection was found in population 2 (Koppana beach) where two ants from the same colony were infected out of 100 individuals.

When pooling all the material, the frequency of infected nests was 42/132 for Serratia, 25/132 for Wolbachia and 5/132 for Cardinium. The observed number of nests with two different bacteria matched the random expectation well based on these frequencies, 9 nests with Serratia and Wolbachia, 3 nests with Serratia and Cardinium and 2 nests with Wolbachia and Cardinium.

As the spreading of endosymbionts should be associated with the dispersal of the ant hosts, we next tested whether the level of genetic differentiation between population pairs $\left(\mathrm{F}_{\mathrm{ST}}\right)$ was correlated with the difference in the infection frequency between the same population pairs. The difference in the prevalence of Wolbachia increased with the genetic distance between populations $\left(r_{\mathrm{m}}=0.62, \mathrm{P}=0.05\right.$, Mantel's test $)$, but no correlation was found for Serratia $\left(r_{m}=0.11, P=0.25\right)$. The correlation between the geographical distance (measured in $\mathrm{km})$ and the difference in the infection frequency was not significant for either Wolbachia $\left(\mathrm{r}_{\mathrm{m}}=0.27, \mathrm{P}=\right.$ $0.17)$ or Serratia $\left(r_{m}=-0.22, P=0.88\right)$. The latter correlation was even negative.

The only indication for a possible association between mitochondrial haplotype and endosymbiont infection was seen in mtDNA haplotype B. It was found in four colonies and three of these carried also Serratia while no other endosymbionts were detected in these colonies. In total seven colonies (from two populations) had the haplotype C, and Wolbachia was detected in two of these, Cardinium in one and Serrata in none. The two colonies with haplotype A and the only colony with haplotype $\mathrm{D}$ had none of the endosymbionts.

\section{Discussion}

We found that the $F$. cinerea ants were infected by multiple endosymbiotic bacterial species Wolbachia, Cardinium and Serratia. The prevalence of both Wolbachia and Serratia varied significantly among the populations and colonies. This variation allowed the investigation of whether the prevalence of endosymbionts was associated with the social structure of colonies $[10,11]$, whether the infections were associated with specific genetic lines defined by mitochondrial haplotypes [13] or genetic differentiation of populations, and whether the endosymbiont species competed with each other or co-infected receptive hosts. This is the first study to reveal Cardinium and Serratia in ants.

\section{Endosymbionts and the genetic structure of populations}

Two of the detected endosymbionts, Wolbachia and Cardinium, are known as reproductive manipulators in insects. If the endosymbiotic bacteria cause cytoplasmic incompatibility in the host, the infection frequency is expected to be either low or high, as intermediate frequencies would commonly lead to incompatibilities [9]. The fraction of infected nests was low (3.8\%) for Cardinium and moderate for Wolbachia (19.0\%). Our results on Wolbachia depart from the general pattern observed in Formica ants, as in several species in northern Europe all or almost all individuals have been infected by the same Wolbachia strains $[15,26]$. The prevalence in $F$. cinerea was low and the wsp primers did not amplify the bacteria, indicating that $F$. cinerea could be infected by a different strain. The frequency of Cardinium infections was very low for reliable statistical comparisons, but the two endosymbionts seemed to coexist as expected on the basis of random association. In other studies, double infections of unrelated manipulative bacterial species have been reported to be relatively rare [1]. The density and location of endosymbionts within the host has been shown to depend on co-infection, as observed for Wolbachia and Spiroplasma, as well as on 
the host genotype and environmental conditions [27,28]. If different bacteria, or different strains of the same bacteria, cause reproductive incompatibility, selection could increase the frequency of all of them and lead to multiple infections as observed for Wolbachia in the ants Formica exsecta [26] and Acromyrmex [29].

Wenseleers et al. [10] proposed that while Wolbachia may have problems invading an ant population with monogynous colonies, it could spread in populations with polygynous colonies. Their data also supported this hypothesis as Wolbachia was found more commonly in polygynous species of South-East Asian ants than in monogynous species. Later, Shoemaker et al. [11] predicted that in monogynous species selection will tend to maintain high rates of infection because of the high costs of incompatible matings. This, indeed, seemed to be the case in Solenopsis invicta fire ants. Thus, the hypotheses make opposing predictions concerning the association between the infection frequency and the level of polygyny. The arguments were based on the fact that some strains of Wolbachia are known to cause cytoplasmic incompatibility in insects, but it should be noted that the effects of endosymbionts on ant reproduction have not been documented. Formica cinerea is known to show social polymorphism in the sense that colonies tend to be monogynous in some populations while polygynous in others $[21,22]$. The colonies in polygynous populations can also form large supercolonies that consist of networks of interconnected nests. Such differences in social organisation were also detected in the present study with genetic relatedness among worker nest mates ranging from 0.04 to 0.59 . However, the fraction of infected $F$. cinerea ants (individuals or colonies) was not significantly correlated with the relatedness. We can conclude that no clear association existed between the endosymbionts and the social type of the colonies.

There are three possible explanations for why the prevalence of Wolbachia in F. cinerea was low compared to the other European Formica ants. First, our material consisted of worker ants and it has been suggested that workers can clear an infection, even though no clearance has been found in several Formica species that have multiple infections $[15,26]$. Infected workers may suffer an energetic cost which harmfully affects the whole colony, both ants and endosymbionts [7]. Some previous ant-Wolbachia studies have revealed that the infection level tends to decrease with development; the worker brood and female reproductives have higher infection levels than the adult workers and males $[7,30]$. Such clearance does not necessarily harm the interests of the bacteria as a non-reproductive worker can be a dead-end to a vertically transmitted endosymbiont. However, due to the large number of worker individuals, they offer a suitable source for horizontal transfer of endosymbionts and it is therefore not evident that clearance is beneficial for the bacteria. The infection frequencies in F. cinerea were so small that it is doubtful whether they could be explained by clearance, and it is reasonable to suggest that not all the nests had infected queens.

Second, the ants may have lost infections due to population processes. For example the Wolbachia prevalence in invasive ant species is lower in the introduced range than the native range $[12,14,31]$. The complete lack of Wolbachia or low level of infection has been considered as a sign of success of ants without the $\mathrm{Wol}$ bachia load in new habitats $[11,31]$. Formica cinerea has distributed to northern latitudes after the withdrawal of the last glacial period and is specialised in living in sandy habitats that often appear as patchy areas. The habitat patches (open sandy areas) are temporary and the populations have been forced to track them, creating local bottlenecks as is seen in invading species. In agreement with this view, genotypic variation indicates past contacts between the $F$. cinerea populations in northern Europe even though they appear isolated today [21]. The low overall level of nucleotide diversity in mtDNA found in this study is also compatible with this view and resembles the situation in several other Formica ants in northern Europe [32].

Third, the low prevalence in $F$. cinerea compared to other Formica species could result from an infection by a different strain of Wolbachia. The commonly used primers for the $w s p$ gene failed to produce any visible band from $F$. cinerea samples even though the primers work well in other Formica ants [[10,15,26], this study]. We also sequenced $16 \mathrm{SrDNA}$ from several species from the Formica rufa group, known to harbour strains wFex1, wFex 2 and wFex 4 as defined by their wsp sequences [15]. The wsp sequences of these strains differ from each other by $10-21 \%$ of nucleotides. The $16 \mathrm{SrDNA}$ sequences from these samples were identical to or differed by only one nucleotide from the common sequences found in $F$. cinerea, and the most divergent $16 \mathrm{SrDNA}$ haplotypes observed from $F$. cinerea differed by about $3 \%$ from each other. $16 \mathrm{SrDNA}$ is more conservative than the $w s p$ gene, and recombination between different Wolbachia strains may make it difficult to infer the type of strain from a single gene. Sequencing of Wolbachia genome from Drosophila simulans has revealed that Wolbachia wRi has the most highly recombining intracellular bacterial genome known to date [33]. Recombination in Wolbachia breaks the anticipated correlations between gene history, genome history and strain phenotype, thus no single sequence can correctly determine relationships between different Wolbachia strains [33]. Furthermore recent finding that 
massive amount of Wolbachia sequences (177 kb) have been transferred into the nuclear genomes of some hosts adds further complexity in interpretation of the infection status [33-35].

Some population pairs showed considerable genetic differentiation as indicated by the pair-wise $\mathrm{F}_{\mathrm{ST}}$ estimates and the genetic differentiation of the hosts was significantly correlated with a difference in Wolbachia prevalence. The two Koppana populations (beach and sand pit) give a good example of this as they showed a significant genetic difference in spite of their close proximity (separated by $1.5 \mathrm{~km}$ ). The clustering of the mtDNA haplotype B in the Koppana sand pit population, even though in only four colonies, agreed with the pattern of differentiation seen in microsatellites. The Koppana populations showed widely different endosymbiont prevalences (Table 1, Figure 1). About $45 \%$ of individuals were infected in Koppana sand pit (pooling all the three bacteria) but only $25 \%$ in Koppana beach. The correlational evidence does not tell whether limited dispersal of the ants has restricted the spreading of the endosymbionts or whether incompatibilities caused by the endosymbionts have restricted the gene flow of the host. Intraspecific comparisons of nearby populations with different social organisation have in other Formica species shown that the polygynous colonies have less genetic variation than the neighbouring monogynous populations, particularly in mitochondrial DNA $[F$. exsecta [23] and F. truncorum [36]]. This has been taken to indicate that polygynous supercolonies may originate through a population bottleneck and grow by budding of colonies with restricted dispersal, as also observed in introduced ant species that form unicolonial populations [e.g. [37]]. In agreement with this, none of the rare mtDNA variants (A, B, C and D) in F. cinerea were found in the most polygynous populations.

\section{Endosymbiont diversity in $F$. cinerea}

Various maternally inherited bacteria are estimated to infect approximately one third of arthropod species [1]. Wolbachia has been found to infect around $66 \%$ of the species whereas other reproductive endosymbionts (Cardinium, Arsenophonus, Spiroplasma) occur in 4\% to $7 \%$ of studied arthropods $[1,38]$. At the population level, the range of Wolbachia infections has been reported from $3 \%$ to $100 \%$, generally being fixed or close to fixation $[1,39]$. Wolbachia infections vary in $F$. cinerea between $1.2 \%-33 \%$ in populations and when taking into consideration the average infection percentage $5.6 \%$ we can conclude that Wolbachia has low prevalence in $F$. cinerea.

Six to seven percent of the studied insects and mites and $22 \%$ of spider species are reported to have Cardinium infection $[40,41]$ and it has been reported from
Hymenoptera, Hemiptera, Diptera, Acari and Aranea $[1,42]$. Cardinium has not been earlier reported from ants even though three ant species (Cataglyphis sp., Messor capitatus, Platythyrea punctata) were included along with 96 other invertebrates in a study where it was screened [40]. We found Cardinium at low frequency (1-2\% of individuals) in F. cinerea. Cardinium is known to induce CI in parasitoid wasps Encarsia spp and in spider mites Eotetranychus suginamensis [43,44], parthenogenesis in parasitoid wasps Encarsia spp [45] and feminization in false spider mites Brevipalpus spp [2]. In predatory mite Metaseiulus occidentalis, Cardinium is reported to enhance the fecundity of the species [46]. Historical evidence for horizontal transfer has been reported for Cardinium [40], even though some studies failed to find evidence for it even between parasitoids and their hosts [e.g. [47]].

Serratia symbiotica is known as a secondary endosymbiont of aphids [25] and was detected in all but one population of $F$. cinerea with the infection percentage varying from $2 \%$ to $42 \%$, and the overall percentage was $33 \%$ of the nests. In several populations Serratia was the most common of the endosymbionts studied here and in Koppana sand pit (population number 5) almost all the colonies (13/16) were infected. A few sequences of Serratia differed clearly from the others (by 1.4\%), indicating two separate bacterial lineages. This difference is similar to that between Serratia haplotypes from F. cinerea and some aphids $(0.4-1.5 \%)$. It is likely that the bacteria have been transferred horizontally both within and between species as has been detected in other S. symbiotica studies $[25,48]$.

The fact that Serratia is found in both ants and aphids could be related to the fact that many ants, including F. cinerea, prey on aphids and also tend them for honeydew. This can offer a potential transmission route because honeydew does not contain only plant sap but also excretions from the aphid. Oral ingestion has been suggested to provide a transmission route also among aphids either via honeydew, squashed aphids or phloem sap of plants heavily populated by aphids [49]. It is not sure whether F. cinerea has Serratia as a true endosymbiont or whether it is only transient gut bacterium in ants. We successfully amplified both Wolbachia and Cardinium from the heads and thoraces of the ants, Wolbachia also from legs, suggesting that these bacteria exist as true endosymbionts. Other Serratia species (e.g. $S$. marcescens) are known to associate with many insects as a pathogen [50]. It will be interesting to explore the role of Serratia in the biology of $F$. cinerea as various gut symbionts have been shown to be a major force in ant evolution [20]. It has also been shown that Wolbachia can be an essential symbiont in insects, providing vitamins to the host [51]. Although many endosymbionts are 
mainly vertically transmitted, many cases of horizontal transfer between host species have been reported. Our study clearly indicates the need for a large scale screening not only for Wolbachia but also for other endosymbionts that are capable for manipulation of the reproduction and sexual bias of the host species.

\section{Conclusions}

We found three endosymbiotic bacteria, Wolbachia, Cardinium and Serratia with significantly varying infection frequencies among Formica cinerea colonies and populations. This is the first report of Cardinium and Serratia in ants. Both Wolbachia and Cardinium are known to manipulate reproduction of their hosts, even though the effects have not been demonstrated in ants. Our discovery of several endosymbionts and co-infections by Wolbachia and Cardinium demonstrate the importance of screening several endosymbionts when evaluating their possible effects on social life and queen-worker conflicts over sex allocation. Whether Serratia is an endosymbiont or a transient gut bacterium in F. cinerea needs to be clarified. All three bacteria had low to moderate prevalence in ants. This differs from the pattern seen earlier in many Formica species in which all worker ants have been infected, and it is likely that F. cinerea carries a different strain of Wolbachia. The ant populations could be divided into two groups, one characterised by highly polygynous nests/ relatedness among worker nest mates $r \leq 0.12$ ) and the other by largely monogynous nests $(r \geq 0.40)$. The prevalence of the endosymbionts did not correlate significantly with the relatedness, suggesting that there is no evident association between the endosymbiont infections and the social type of the colonies at the geographical scale studied. The difference in Wolbachia prevalence correlated significantly with the pair-wise genetic distance of populations suggesting that spreading of the bacteria is connected to the isolation of the host populations. However, it is not possible to conclude whether limited dispersal of the ants has restricted the spreading of the endosymbionts or whether incompatibilities caused by the endosymbionts have restricted the gene flow of the host.

\section{Methods}

\section{Samples}

The material came from 656 worker ants sampled in 10 Formica cinerea populations (Table 1) around Oulu region in central Finland in September and October 2001. We sampled 3 to 22 colonies per population and five workers per colony. Only eight populations with at least nine nests were used for the population analyses. The distance between the sampled nests was at least 5 metres to increase the probability that different colonies were selected. The distance between populations varied from 1.5 to $50 \mathrm{~km}$. Samples were stored in $90 \%$ ethanol (which helps to separate the ectoparasitic mites), and we also visually checked to make sure that the ants did not carry any mites. Genomic DNA was extracted using the Qiagen DNeasy Tissue Kit that purifies also mitochondrial and bacterial DNA. Individual ants were placed in separate $1.5 \mathrm{ml}$ eppendorf tubes that were dipped in liquid nitrogen and ground by using disposable microtube pestles. The following steps in DNA extraction were done according to manufacturer's protocol for animal tissue. DNA concentration and purity of samples were measured by spectrophotometer (Eppendorf biophotometer) and concentration values ranged between $20-60 \mathrm{ng} / \mathrm{ul}$ (in final volume of $200 \mathrm{ul}$ ) and purity of DNA was measured as ratio of absorbances at wavelengths of 260 and 280 $\mathrm{nm}$, the values ranged between 1.5-1.8 when using sterile water as diluent. We also checked the presence of Wolbachia and Cardinium in different body parts separately and succesfully amplified and sequenced them from DNA extracted from both heads and thoraces. Wolbachia was also found in gasters and legs of the ants.

\section{Mitochondrial sequences}

Primer pair cytb3-tRNA-Ser [52] was used to amplify about 500 bp of mitochondrial DNA including the 3' region of the gene cytochrome oxidase $b$, short intervening region and 5' sequence of the gene tRNA-Ser. The total volume of the PCR reactions was $15 \mathrm{ul}$ and contained $1 \times$ PCR buffer, $1.5 \mathrm{mM} \mathrm{MgCl} 2,0.25 \mathrm{mM}$ of each nucleotide, $0.5 \mu \mathrm{M}$ primers cytb and tRNASer, 0.3 units of enzyme (Dynazyme II by Finnzymes). The following PCR program was used for amplification: denaturation at $94^{\circ} \mathrm{C}$ for $3 \mathrm{~min}$, $94^{\circ} \mathrm{C}$ for $1 \mathrm{~min}, 50^{\circ} \mathrm{C} 50 \mathrm{sec}, 72^{\circ} \mathrm{C}$ for $1 \mathrm{~min}$, cycles 30 , final extension at $72^{\circ} \mathrm{C}$ for 10 min using PCR machine PTC-200. The PCR products were run in $2 \%$ agarose gels at $100 \mathrm{~V}$ for $2-3$ hours to verify the success of amplification. Thereafter they were run on Single Strand Conformation Polymorphism (SSCP) gels to study haplotype variation. Three gel temperatures were tested, $+4^{\circ} \mathrm{C},+15^{\circ} \mathrm{C}$ and $+37^{\circ} \mathrm{C}$ and temperature $+37^{\circ} \mathrm{C}$ gave the best results and was used for all the samples. Prerun of SSCP was done at $200 \mathrm{~V}$ for 30 minutes to warm up the acrylamide gels and to remove additional traces of acrylamide from wells where denatured samples were run for 5 hours at $200 \mathrm{~V}$. The gels were stained using the $\mathrm{AgNO}_{3}$ method [53] and dried on frames in room temperature for two days before scoring. One individual per nest and the samples that had a deviating banding pattern on SSCP were selected for further sequencing. To strengthen the intensity of the amplification products for direct sequencing, we did secondary PCR by using $1 \mathrm{ul}$ of the initial PCR product as a template. Otherwise the protocol was the same as in the first PCR. Secondary PCR products were purified by using the MinElute kit (Qiagen) for direct sequencing reactions where $1 / 8$ part reactions of Big Dye Terminator 
v 3.0 were done according to the instructions of the manufacturer (Applied Biosystems, Foster City, CA). Sequencing reactions were purified by the Sephadex-method (Sigma Aldrich) before the run in the capillary sequencer ABI3730. Sequences were inspected by the program Sequencher v 4.7 (Gene Codes Corporation) and alignments were done by ClustalW in MEGA v 3.1 [54].

\section{Microsatellites}

Fifteen microsatellite loci were tested with gradient PCR $\left(45-64^{\circ} \mathrm{C}\right)$ and the products were run in $2 \%$ agarose gel and in ABI377. Four highly polymorphic loci (Fe13, Fe16, Fe38, FL20) $[55,56]$ were selected. The primer pairs Fe13, FL20 and FL20 had been used in an earlier study on $F$. cinerea $[21,22]$. The microsatellite PCR-program consisted of predenaturation at $94^{\circ} \mathrm{C}$ for $3 \mathrm{~min}, 35$ cycles consisting $94^{\circ} \mathrm{C}$ for $1 \mathrm{~min}, 55^{\circ} \mathrm{C}$ for $40 \mathrm{sec}$ (for Fe13 primer pair $53^{\circ} \mathrm{C}$ for $40 \mathrm{sec}$ ), $72^{\circ} \mathrm{C}$ for $50 \mathrm{sec}$. In the end an elongated extension time of 45 minutes was applied at $72^{\circ} \mathrm{C}$ to assure the proper extension of PCR products. PCR products were run in an ABI prism 377 Sequencer and fragments were analysed by using the GeneScan and Genotyper software packages (Applied Biosystems, Foster City, CA)

\section{Endosymbionts}

The same DNA samples that were used in the analysis of nuclear and mitochondrial markers were studied for several endosymbionts. Thus we could be certain that the DNA extractions were successful and the genomic DNA was of good quality. The following primer pairs were tested for Wolbachia by direct PCR: wsp 81F-691R [57], Wolb 16SrDNA [12] and general 16SrDNA [58]. PCR reactions for the $w s p$-primer pair contained $1 \times$ PCR buffer, $2 \mathrm{mM} \mathrm{MgCl}, 0.25 \mathrm{mM}$ of each nucleotide, $0.5 \mu \mathrm{M}$ of primer $81 \mathrm{~F}$ and $691 \mathrm{R}$, and $0.3 \mathrm{U}$ of DynazymeII (Finnzymes). Gradient PCR $\left(50^{\circ} \mathrm{C}-60^{\circ} \mathrm{C}\right)$ was used to test optimal amplification conditions for Wsp by using $F$. cinerea individuals and positive controls ( $F$. aquilonia and $F$. lemani individuals) as test samples. The annealing temperature that gave the strongest bands (for positive controls) was selected for use in a further PCR program for $w s p$. In addition, primer pairs were used for several additional positive controls from different Formica species, including F. polyctena (colonies U-11 and S-33 studied for mtDNA [32] and for wsp [15]), F. rufa (S-35), F. lugubris (S-42, U-36), F. pratensis (S-44). The PCR program included steps of denaturation at $94^{\circ} \mathrm{C}$ for $3 \mathrm{~min}, 94^{\circ} \mathrm{C} 1 \mathrm{~min}, 53^{\circ} \mathrm{C} 50 \mathrm{sec}, 72^{\circ}$ $\mathrm{C} 1 \mathrm{~min}$, cycled 40 times, final extension at $72^{\circ} \mathrm{C}$ for 10 min. Positive (F. lemani and F. aquilonia) and negative (sterile water) controls were included in all the PCRruns. The amount of template used was $1 \mathrm{ul}(20 \mathrm{ng} / \mathrm{ul})$.

Hemi-nested PCR [46] was used to screen several endosymbiotic bacteria. In the first PCR reactions we used universal primer pair 27Forward 5'-AGAGTTTGATCMTGGCTCAG-3' and 1513Reverse 5'-ACGGYTACCTTGTTACGACTT-3' for 16SrDNA that amplify a $1.5 \mathrm{~kb}$ fragment from all eubacteria [59]. In the second PCR, the diluted PCR-product (1:46) was used as a template for each bacteria specific primer pair that amplify fragments from the Ricketsia (27F and Rick16SR 5'CATCCATCAGCGATAAATCTTTC-3') [60], Spiroplasma (27F and TKSSsp 5'-TAGCCG TGGCT TTCTGGTAA -3') [61], Buchnera (Buch16S1F 5'GAGCTTGCTCTCTTTGTCGGCAA-3' and Buch16S1R 5'-CTTCTGCGGGTAACGTCACGAA-3') [60], PASS=Candidatus Serratia symbiotica (27F and PASScmp: 5'GCAATGTCTTATTAACACAT-3') [50], Cardinium (CLOf 5'-GCGGTGTAAAATGAGCGTG -3' and CLOr1 5'- ACCTMTTCTTAACTCAAGCCT -3' and CLOF and CLOr2 5'-TGTGTACAAGGTCCG AGA ACG -3') [46], EPS (EPS-f 5'-TACAATCTTTATTAACCCATGTT -'3 and EPS-r 5'- TTCAAAGTAGCAAAATACATTC-3') [45] and Wolbachia (w76F 5'- TTGTAGCCTGCTATGGTATAACT -3' and w1012R 5' GAATAGGTATGATTTTCATGT -3') [58]. A PCR reaction for each primer pair was done according to the protocol described in the references. In each PCR plate we used sterile water as a negative control. As positive controls we used samples that were known to contain Wolbachia (F. lemani, F. aquilonia), but no positive control for the other bacteria was available in the beginning. In later steps samples that were shown to include the desired bacteria were used as positive control. PCR products were run on $1.5 \%$ agarose gel stained with ethidium bromide and the bands were visualized under ultraviolet illumination. The bands of a correct size were cut and purified with the MinElute Gel Extraction Kit (Qiagen). Purified DNA was cloned using TOPO TA-cloning kit (Invitrogen) and after the extraction of plasmids the success of cloning was determined by PCR $[1 \times$ buffer, $0.25 \mathrm{mM}$ of each nucleotide, 0.5 $\mathrm{uM}$ of primer M13F and M13R and Dynazyme II (Finnzymes) $0.3 \mathrm{U}$ ] done in the total volume of $15 \mu \mathrm{l}$. The PCR program included the steps of denaturation at $94^{\circ} \mathrm{C}$ for $5 \mathrm{~min}, 35$ cycles at $94^{\circ} \mathrm{C}$ for $1 \mathrm{~min}$, at $46^{\circ} \mathrm{C}$ for 50 sec, at $72^{\circ} \mathrm{C}$ for $1 \mathrm{~min}$ and final extension at $72^{\circ} \mathrm{C}$ for 10 min. Three microlitres of the product was run on $1.5 \%$ agarose gel to verify the success of cloning and the correct size of the band by using M13 forward and reverse primers flanking the insertion site in the cloning vector (pCR 2.1-TOPO). The rest of the reaction was purified with the MinElute 96 UF PCR Purification Kit (Qiagen). Both strands were sequenced from PCR products from one to five clones per individual by a vector-specific primer pair (included in the TOPO TA-cloning kit) and sequencing was done with the Big Dye Ready Reaction Kit as $1 / 8$ part reaction according to the instructions of 
the manufacturer (Applied Biosystems). Sequences were inspected by the program Sequencher v. 4.7 and the alignments were done in MEGA v 3.1 [54].

\section{Statistical analyses}

The genetic relatedness ( $r$ ) and inbreeding $(F)$ coefficients for ant nests and populations were calculated using the algorithms of Queller and Goodnight [62] and Pamilo [24]. Relatedness is the probability of allele sharing between individuals above the average probability given by the gene frequencies in the population. Genetic diversity was analysed using the GENEPOP package version on the web [63] and genetic differentiation was estimated as $\mathrm{F}_{\mathrm{ST}}$ [64] by sampling repeatedly ( 20 repeats) one individual from each nest. The $\mathrm{F}_{\mathrm{ST}}$ estimates between populations were tested by comparing the initial estimates against the distribution obtained by permutation of the nests (100 times). The genetic distances and phylogenetic analyses were conducted using MEGA version 3.1 [54]. The haplotype network scheme for mitochondrial DNA was constructed by using the statistical parsimony method implemented in the program TCS v. 1.21. Other statistical analyses were done by using the SPSS (v 16.0) software program.

\section{Additional material}

Additional file 1: UPGMA clustering of populations based on the $\mathrm{F}_{\mathrm{ST}}$ estimates. Relatedness values are shown for the populations.

Additional file 2: Scheme of mitochondrial haplotype network for $F$. cinerea individuals. The lines separating the haplotypes involve one nucleotide change.

Additional file 3: The neighbour-joining tree of Wolbachia $16 \mathrm{~S}$ rDNA sequences from $\boldsymbol{F}$. cinerea. The tree has sequences (896 bp) amplified from $F$. cinerea in this study and three sequences from GenBank. The tree is based on distances estimated by using the Kimura's 2-parameter method with gaps and missing data excluded from pairwise comparisons. The numbers on the nodes represent the bootstrap percentages from 1,000 replications.

Additional file 4: Best matches among GenBank sequences for Wolbachia from $\boldsymbol{F}$. cinerea. The matches are based on results from a BLAST search.

Additional file 5: The neighbour-joining tree of Wolbachia 16SrDNA sequences from Formica ants and other arthropods. The tree

compares haplotypes obtained from F. cinerea and other Formica ants in this study and 16 sequences taken from GenBank.

Additional file 6: The Genbank matches for Cardinium sequence

from $\boldsymbol{F}$. cinerea. The matches are based on results from a BLAST search.

Additional file 7: The best matches among GenBank sequences for Candidatus Serratia symbiotica from $F$. cinerea. The matches are based on results from a BLAST search.

Additional file 8: The neighbour-joining tree of Candidatus $S$. symbiotica sequences. The tree has sequences (471 bp) amplified from $F$. cinerea in this study and one sequence from GenBank. The tree is based on distances estimated by using the Kimura's 2-parameter method with gaps and missing data excluded from pair-wise comparisons. The numbers on the nodes represent the bootstrap percentages from 1,000 replications.

\section{Acknowledgements}

We thank our lab technician Riitta Jokela for valuable work. Financial support was provided by the Academy of Finland to PP and AS. Personal grants were admitted from the Kuopio Naturalist Society and the Science Foundation from the University of Oulu to AS.

\section{Author details}

${ }^{1}$ Department of Biology, P.O. Box 3000, University of Oulu 90014, Oulu, Finland. ${ }^{2}$ Department of Biological and Environmental Sciences, University of Helsinki 00014, P.O. Box 65, Helsinki, Finland.

\section{Authors' contributions}

AS was responsible for the laboratory work, bacteria identifications, analysis of the microsatellites, constructed the phylogenies and mt haplotype network and drafted the manuscript. PP coordinated the study, carried out the population genetic studies and helped to draft the manuscript. The final version of the manuscript was read and approved by both authors.

\section{Competing interests}

The authors declare that they have no competing interests.

Received: 12 February 2010 Accepted: 1 November 2010

Published: 1 November 2010

\section{References}

1. Duron O, Bouchon D, Boutin S, Bellamy L, Zhou L, Engelstädter J, Hurst GD: The diversity of reproductive parasites among arthrops: Wolbachia do not walk alone. BMC Biol 2008, 6:27.

2. Kikuchi $Y$ : Endosymbiotic bacteria in insects: their diversity and culturability. Microbes Environ 2009, 24:195-204.

3. Werren JH: Biology of Wolbachia. Annu Rev Entomol 1997, 42:537-609.

4. Giorgini M, Bernardo U, Monti MM, Nappo AG, Gebiolea M: Rickettsia symbionts cause parthenogenetic reproduction in the parasitoid wasp Pnigalio soemius (Hymenoptera: Eulophidae). Appl Environ Microbiol 2010, 76:2589-2599.

5. Kenyon SG, Hunter MS: Manipulation of oviposition choice of the parasitoid wasp, Encarsia pergandiella, by the endosymbiotic bacterium Cardinium. J Evol Biol 2007, 20:707-716.

6. Keller L, Liautard C, Reuter M, Brown WD: Sex ratio and Wolbachia infection in the ant Formica exsecta. Heredity 2001, 87:227-233.

7. Van Borm S, Wenseleers T, Billen J, Boomsma JJ: Wolbachia in leafcutter ants: a widespread symbiont that may induce male killing or incompatible matings. J Evol Biol 2001, 14:805-814.

8. Lombardo MP: Access to mutualistic endosymbiotic microbes: an underappreciated benefit of group living. Behav Ecol Sociobiol 2008, 62:479-497.

9. Turelli M: Evolution of incompatibility-inducing microbes and their hosts. Evolution 1994, 48:1500-1513.

10. Wenseleers T, Ito F, Van Borm S, Huybrechts R, Volckaert F, Billen J: Widespread occurrence of the micro-organism Wolbachia in ants. Proc $R$ Soc Lond B 1998, 265:1447-1452.

11. Shoemaker DD, Ross KG, Keller L, Vargo EL, Werren JH: Wolbachia infections in native and introduced populations of fire ants (Solenopsis spp.). Insect Mol Biol 2000, 9:661-673.

12. Wenseleers T, Billen J: No evidence for Wolbachia-induced parthenogenesis in the social Hymenoptera. J Evol Biol 2000, 13:277-280.

13. Ahrens ME, Shoemaker D: Evolutionary history of Wolbachia infections in the fire ant Solenopsis invicta. BMC Evol Biol 2005, 5:35.

14. Bouwma AM, Ahrens ME, DeHeer CJ, Shoemaker DD: Distribution and prevalence of Wolbachia in introduced populations of the fire ant Solenopsis invicta. Insect Mol Biol 2006, 15:89-93.

15. Viljakainen $L$, Reuter $M$, Pamilo P: Wolbachia transmission dynamics in Formica wood ants. BMC Evol Biol 2008, 8:55.

16. De Souza RF, Silva Ramalho JD, de Castro Morini MS, Caldas Wolff JL, Carvalho Araújo R, Mascara D: Identification and characterization of Wolbachia in Solenopisis seavissima fire ants (Hymenoptera: Formicidae) in Southeastern Brazil. Curr Microbiol 2009, 58:189-194.

17. Stoll S, Gadau J, Gross R, Feldhaar H: Bacterial microbiota associated with ants of the genus Tetraponera. Biol J Linn Soc 2007, 90:399-412. 
18. Pinto-Tomás AA, Anderson MA, Suen G, Stevenson DM, Chu FST, Cleland WW, Weimer PJ, Currie CR: Symbiotic nitrogen fixation in the fungus gardens of leaf-cutter ants. Science 2009, 326:1120-1123.

19. Zientz E, Feldhaar $H$, Stoll S, Gross R: Insights into the microbial world associated with ants. Arch Microbiol 2005, 184:199-206.

20. Russell JA, Moreau CS, Goldman-Huertas B, Fujiwara M, Lohman DL, Pierce NE: Bacterial gut symbionts are tightly linked with the evolution of herbivory in ants. Proc Natl Acad Sci USA 2009, 106:21236-21241.

21. Goropashnaya AV, Seppä P, Pamilo P: Social and genetic characteristics of geographically isolated populations in the ant Formica cinerea. Mol Ecol 2001, 10:2807-2818.

22. Zhu D, Chapuisat M, Pamilo P: Highly variable social organization of colonies in the ant Formica cinerea. Hereditas 2003, 139:7-12.

23. Gyllenstrand N, Corander J, Pamilo P: Coexistence of the social types: genetic population structure in the ant Formica exsecta. Evolution 2004 58:2462-2471.

24. Pamilo P: Genotypic correlation and regression in social groups: multiple alleles, multiple loci and subdivided populations. Genetics 1984 107:307-320.

25. Moran N, Russell JA, Koga R, Fukatsu T: Evolutionary relationships of three new species of Enterobacteriaceae living as symbionts of aphids and other insects. Appl Environ Microbiol 2005, 71:3302-3310.

26. Reuter M, Keller L: High levels of multiple Wolbachia infection and recombination in the ant Formica exsecta. Mol Biol Evol 2003, 20:748-753.

27. Kondo N, Shimada M, Fukatsu T: Infection density of Wolbachia endosymbiont affected by co-infection and host genotype. Biol Lett 2005 1:488-491.

28. Mouton L, Henri $H$, Charif $D$, Boulétreau M, Vavre F: Interaction between host genotype and environmental conditions affects bacterial density in Wolbachia symbiosis. Biol Lett 2007, 3:210-213.

29. Van Borm S, Wenseleers T, Billen J, Boomsma JJ: Cloning and sequencings of wsp encoding gene fragments reveals a diversity of co-infecting Wolbachia strains in Acromyrmex leaf-cutter ants. Mol Phylogenet Evol 2002, 26:102-109.

30. Wenseleers T, Sundström L, Billen J: Deleterious Wolbachia in the ant Formica truncorum. Proc R Soc Lond B 2002, 269:623-629.

31. Reuter M, Pedersen JS, Keller L: Loss of Wolbachia infection during colonisation in the invasive Argentine ant Linepithema humile. Heredity 2005, 94:364-369.

32. Goropashnaya AV, Fedorov VB, Pamilo P: Recent speciation in the Formica rufa group ants (Hymenoptera, Formicidae): inference from mitochondrial DNA phylogeny. Mol Phylogenet Evol 2004, 32:198-206.

33. Klasson L, Westberg J, Sapountzis $P$, Näslund $K$, Lutnaes $Y$, Darby AC, Veneti Z, Chen L, Braig HR, Garrett R, Bourtzis K, Andersson SGE: The mosaic genome structure of the Wolbachia wRi strain infecting Drosophila simulans. Proc Natl Acad Sci USA 2009, 106:5725-5730.

34. Nikoh N, Tanaka K, Shibata F, Kondo N, Hizume M, Shimada M, Fukatsu T: Wolbachia genome integrated in an insect chromosome: Evolution and fate of laterally transferred endosymbiont genes. Genome Res 2008, 18:272-280.

35. Dunning Hotopp JC, Clark ME, Oliveira DCSG, Foster JM, Fischer P, Muñoz Torres MC, Giebel JD, Kumar N, Ishmael N, Wang S, Ingram J, Nene RV, Shepard J, Tomkins J, Rickards S, Spiro DJ, Ghedin E, Slatko BE, Tettelin H, Werren $\mathrm{JH}$ : Widespread lateral transfer from intracellular bacteria to multicellular eukaryotes. Science 2007, 317:1753-1756.

36. Gyllenstrand N, Seppä P, Pamilo P: Restricted gene flow between two social forms in the ant Formica truncorum. J Evol Biol 2005, 18:978-984.

37. Tsutsui ND, Case TJ: Population genetics and colony structure of the Argentine ant (Linepithema humile) in its native and introduced ranges. Evolution 2001, 55:976-985.

38. Hilgenboecker $\mathrm{K}$, Hammerstein $\mathrm{P}$, Schlattmann $\mathrm{P}$, Werren JH: How many species are infected with Wolbachia? -a statistical analysis of current data. Microbiol Letter 2008, 281:215-220.

39. Tagami $Y$, Miura K: Distribution and prevalence of Wolbachia in Japanese populations of Lepidoptera. Insect Mol Biol 2004, 13:359-364.

40. Zchori-Fein E, Perlman SJ: Distribution of the bacterial symbiont Cardinium in arthropods. Mol Ecol 2004, 13:2009-2016.

41. Duron O, Hurst GDD, Hornett EA, Josling JA, Engelstadter J: High incidence of the maternally inherited bacterium Cardinium in spiders. Mol Ecol 2008, 17:1427-1437.
42. Nakamura Y, Kawai S, Yukuhiro F, Ito S, Gotoh T, Kisimoto R, Yanase T, Matsumoto Y, Kageyama D, Noda H: Prevalence of Cardinium bacteria in planthoppers and spider mites and taxonomic revision of "Candidatus Cardinium hertigii" based on detection of a new Cardinium group from biting midges. Appl Environ Microbiol 2009, 75:6757-6763.

43. Hunter MS, Perlman SJ, Kelly SE: A bacterial symbiont in the Bacteroidetes induces cytoplasmc incompatibility in the parasitoid wasp Encarsia pergandiella. Proc R Soc Lond B 2003, 270:2185-2190.

44. Gotoh T, Noda H, Ito S: Cardinium symbionts cause cytoplasmic incompatibility in spider mites. Heredity 2007, 98:13-20.

45. Zchori-Fein E, Gottlieb Y, Kelly SE, Brown JK, Wilson JM, Karr TL, Hunter MS: A newly discovered bacterium associated with parthenogenesis and a change in host selection behavior in parasitoid wasps. Proc Natl Acad Sci USA 2001, 98:12555-12560.

46. Weeks $A R$, Velten $R$, Stouthamer R: Incidence of a new sex-ratio-distorting endosymbiotic bacterium among arthropods. Proc $R$ Soc Lond B 2003, 270:1857-1865.

47. Matalon Y, Katzir N, Gottlieb Y, Portnoy V, Zchori-Fein E: Cardinium in Plagiomerus diaspidis (Hymenoptera: Encyrtidae). J Invertebr Pathol 2007, 96:106-108.

48. Russell JA, Latorre A, Sabater-Muñoz B, Moya A, Moran NA: Side-stepping secondary symbionts: widespread horizontal transfer across and beyond the Aphidoidea. Mol Ecol 2003, 12:1061-1075.

49. Fukatsu T, Nikoh N, Kawai R, Koga R: The secondary endosymbiotic bacterium of the pea aphid Acyrthosiphon pisum (Insecta: Homoptera). Appl Environ Microbiol 2000, 66:2748-2758.

50. Lundgren JG, Lehman RM, Chee-Sanford J: Bacterial communities within digestive tracts of ground beetles (Coleoptera: Carabidae). Ann Entom Soc Amer 2007, 100:275-282.

51. Hosokawa T, Koga R, Kikuchi Y, Meng X-Y, Fukatsu T: Wolbachia as a bacteriocyte-associated nutritional mutualist. PNAS 2009.

52. Crozier $\mathrm{RH}$ : The cytochrome $b$ region in the mitochondrial DNA of the ant Tetraponera rufoniger: sequence divergence in Hymenoptera may be associated with nucleotide content. J Mol Evol 1994, 38:282-294.

53. Bassam BJ, Caetano-Anolles G, Gresshoff PM: Fast and sensitive silver staining of DNA in polyacrylamide gels. Anal Biochem 1991, 196:80-83.

54. Kumar S, Tamura K, Nei M: MEGA3: Integrated software for Molecular Evolutionary Genetics Analysis and sequence alignment. Brief Bioinform 2004, 5:150-163.

55. Chapuisat M: Characterization of microsatellite loci in Formica lugubris $B$ and their variability in other ant species. Mol Ecol 1996, 5:599-601.

56. Gyllenstrand N, Gertsch PJ, Pamilo P: Polymorphic microsatellites DNA markers in the ant Formica exsecta. Mol Ecol Notes 2002, 2:67-69.

57. Braig HR, Zhou W, Dobson SL, O'Neill S: Cloning and characterization of a geneencoding the major surface protein of the bacterial endosymbiont Wolbachia pipientis. J Bacteriol 1998, 180:2373-2378.

58. O'Neill SL, Giordano R, Colbert AM, Karr TL, Robertson HM: 16 S rDNA phylogenetic analysis of the bacterial endosymbionts associated with cytoplasmic incompatibility in insects. Proc Natl Acad Sci USA 1992, 89:2699-2702.

59. Weisburg WG, Barns SM, Pelletier DA, Lane DJ: 16 S ribosomal DNA amplification for phylogenetics study. J Bacteriol 1991, 173:697-703.

60. Fukatsu T, Tsuchida T, Nikoh N, Koga R: Spiroplasma symbiont of the pea aphid, Acyrthosiphon pisum (Insecta: Homoptera). Appl Environ Microbiol 2001, 67:1284-1291.

61. Fukatsu T, Nikoh N: Endosymbiotic microbiota of the bamboo pseudococcid Antonina crawii (Insecta: Homoptera). Appl Environ Microbiol 2000, 66:643-650

62. Queller DC, Goodnight KF: Estimating relatedness using genetic markers. Evolution 1989, 43:258-275

63. Raymond M, Rousset F: GENEPOP (version 1.2): population genetics software for exact tests and ecumenicism. J Hered 1995, 86:248-249.

64. Weir BS, Cockerham CC: Estimating F-statistics for the analysis of population structure. Evolution 1984, 38:1358-1370.

doi:10.1186/1471-2148-10-335

Cite this article as: Sirviö and Pamilo: Multiple endosymbionts in populations of the ant Formica cinerea. BMC Evolutionary Biology 2010 10:335. 